\title{
Functional Monomers and Polymers CLXVIII. Syntheses and Photoreactions of Poly(methacrylate)s Containing Thymine Bases
}

\author{
Minoo Jalili Moghaddam, Shigeo HozUmi, Yoshiaki InAKI, \\ and Kiichi TAKEMOTO \\ Department of Applied Fine Chemistry, Faculty of Engineering, \\ Osaka University, Suita, Osaka 565, Japan
}

(Received August 15, 1988)

\begin{abstract}
Poly(methacrylate)s having thymine derivatives were studied for photodimerizations of thymine units in solution and in the film state, and photolithographic sensitivity tests for their applicability to negative type photoresists. In these homopolymers and copolymers, thymine bases were attached to the polymer chain at positions $\mathrm{N}^{1}$ or $\mathrm{N}^{3}$. Among these polymers, the alternate copolymer indicated the highest photosensitivity. The results are discussed from the viewpoint of intra- and/or intermolecular photodimerization and the quantum yields in solution and in the film state.
\end{abstract}

KEY WORDS Deep UV Photoresist / Negative Type Photoresist / Poly(methacrylate) / Thymine Base Derivative / Photosensitivity / Quantum Yield / Intermolecular Photodimerization / Intramolecular Photodimerization / Photo-crosslinking /

The photolithographic process is one of the most essential steps or probably the key process in microelectronics fabrication technology. Therefore researche on inventing new materials for photolithographic processes with high sensitivity, good resolution and dry etch resistance, has received much attention in these years. ${ }^{1,2}$ We have studied photoresists for deep-UV region and synthesized various polymers containing pyrimidine bases pendant to the polymer chain. ${ }^{3-7}$ It is well known that pyrimidine bases undergo photodimerization by exposure of the UV light above $270 \mathrm{~nm}$, and also readily reverse to their monomers by UV light at shorter wavelengths (Scheme 1). Among the synthesized polymers, copolymers of methacrylates containing thymine or 6cyano-uracil with butadiene exhibit high sensitivity and excellent resolution characteristics as negative type photoresists. ${ }^{7}$ The photolyses of these polymers upon UV irradiation above $270 \mathrm{~nm}$ cause intramolecular or intermolecular dimerization of the pyrimidine bases competitively, where the intramolecular self association of the pyrimidine bases is an important factor for photodimerization of these polymers. $^{5}$

In order to obtain photoresists with excel-
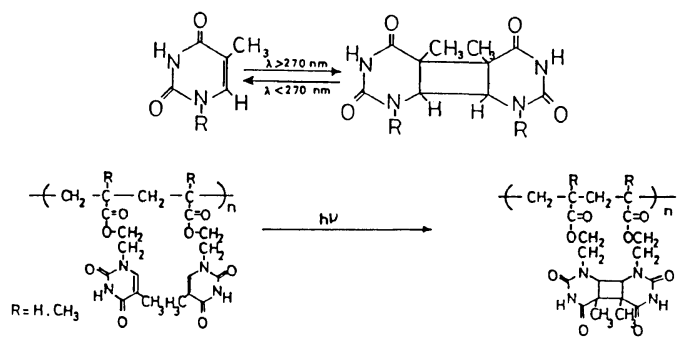

Scheme 1.

\footnotetext{
${ }^{\dagger}$ Part CLXVII of the series: M. Miyata, T. Tsuzuki, K. Takemoto, and M. Kamachi, Polym. J., 20, 711 (1988).
} 

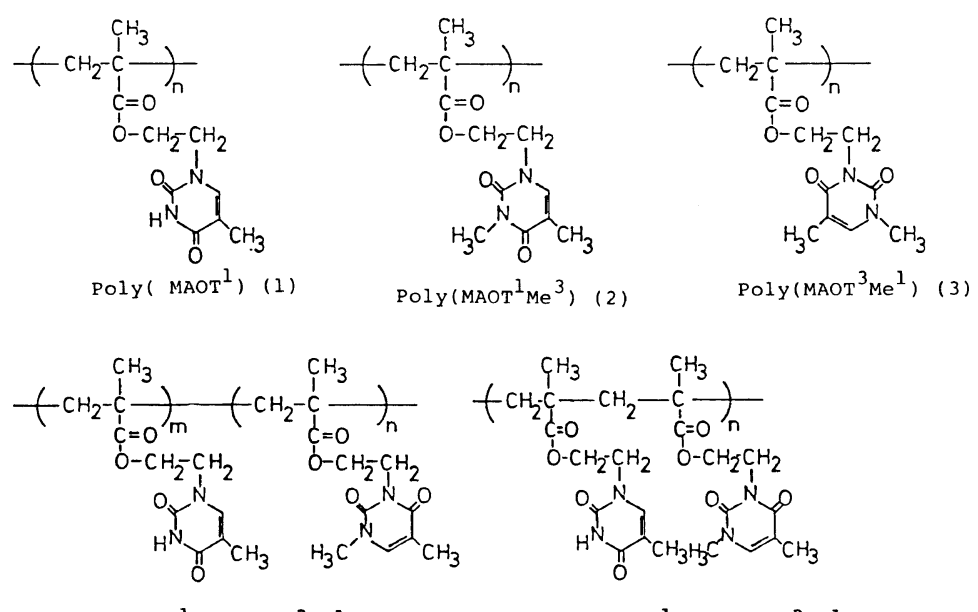

POLY $\left(\right.$ MAOT $^{1}-$ CO-MAOT $\left.^{3} \mathrm{Me}^{1}\right)(4 \mathrm{a}-4 \mathrm{e})$

POLY $\left(\right.$ MAOT $^{1}$-alt-MAOT ${ }^{3} \mathrm{Me}^{1}$ )

(5)

Figure 1. Synthetic poly(methacrylate)s containing thymine units in the side chain.

lent resolution and high sensitivity, it is necessary to suppress intramolecular reactions and enhance the intermolecular photodimerization of pyrimidine bases for effective photocrosslinking of the polymer chains. In the present paper, poly(methacrylate)s having various thymine derivatives were prepared based on molecular models (Figure 1). Homopolymers have thymine bases at position $\mathrm{N}^{1}$ [poly$\left.\left(\mathrm{MAOT}^{1}\right) ;(1,2)\right]$ and $\mathrm{N}^{3}\left[\operatorname{poly}\left(\mathrm{MAOT}^{3} \mathrm{Me}^{1}\right)\right.$; (3).] The copolymers were random $(\mathbf{4 a - 4 e )}$ $\left[\right.$ poly $\left(\mathrm{MAOT}^{1}{ }^{-}\right.$co-MAOT $\left.\left.^{3} \mathrm{Me}^{1}\right)\right]$ and alternate (5) $\left[\right.$ poly $\left(\mathrm{MAOT}^{1}\right.$-alt-MAOT $\left.\left.{ }^{3} \mathrm{Me}^{1}\right)\right]$ copolymers composed of monomers of MAOT $^{1}$ and $\mathrm{MAOT}^{3} \mathrm{Me}^{1}$. The photoreactions and the lithographic properties of these polymers were studied and the results are dicussed from the viewpoint of intermolecular or intramolecular photodimerization.

\section{EXPERIMENTAL}

\section{Materials}

\section{Monomer Synthesis}

1-(2-Hydroxyethyl)thymine (10). Methacrylonitrile $(75 \mathrm{ml}, 0.89 \mathrm{~mol})$ was added to ethanolamine $(54 \mathrm{ml} ; 0.89 \mathrm{~mol})$, cooled in an ice bath. The mixture was stirred at room temperature for $4 \mathrm{~h}$, and then refluxed for $4 \mathrm{~h}$ to give the viscous oily product, 3-(2-hydroxyethylamino)-2-methyl-propionitrile (6).

The obtained 6 dissolved in $7 N$ hydrochloric acid $(150 \mathrm{ml})$ was added to $260 \mathrm{ml}$ cool aqueous solution of potassium cyanate $(89 \mathrm{~g})$. The resulting solution was stirred at room temperature for $12 \mathrm{~h}$, and then evaporated to dryness. The residue was extracted with ethanol, and the solvent was evaporated to give the oily product, 1-(2-hydroxyethyl)-1-(2cyanopropyl)urea (7).

An aqueous solution of 7 in methanolic hydrocholoric acid (water; $400 \mathrm{ml}$, methanol; $400 \mathrm{ml}, 35 \%$ hydrochloric acid; $140 \mathrm{ml}$ ) was refluxed for $5 \mathrm{~h}$, and the solvent was evaporated to dryness. The solid residue was extracted with ethanol, and the solvent was evaporated to give 5,6-dihydro-1-(2-hydroxyethyl)thymine (8), which was crystallized by cooling, yield; $80 \%(120 \mathrm{~g})$.

Compound 8 ( $86 \mathrm{~g} ; 0.5 \mathrm{~mol})$ was dissolved in acetic acid $(250 \mathrm{ml})$, and bromine $(80 \mathrm{~g}$; $0.5 \mathrm{~mol})$ in acetic acid $(120 \mathrm{ml})$ was added dropwise to the solution under reflux. After evolution of $\mathrm{HBr}$ gas $(7 \mathrm{~h})$, sodium acetate $(123 \mathrm{~g} ; 1.5 \mathrm{~mol})$ was added to the reaction mixture, and refluxed for additional $5 \mathrm{~h}$. The solvent was removed under reduced pressure to dryness. The residual solid was then extract- 
ed with ethyl acetate, and the extract was evaporated to dryness. Recrystallization from ethanol gave 9 in $80 \%$ yield $(80 \mathrm{~g})$. The obtained (9) was hydrolyzed with $120 \mathrm{ml}$ of $12 \mathrm{~N}$ hydrochloric acid in $500 \mathrm{ml}$ of methanol, under reflux. After $3 \mathrm{~h}$, the solvent was removed under reduced pressure and the residue was crystallized from ethanol to give white crystals, 1-(2-hydroxyethyl)thymine (10), identified by IR and NMR spectra in the litterature. ${ }^{3}$

I-Methyl-thymine (11). This compound was synthesized by the same method as that described for compound 10, except that methylamine was used as the starting material instead of ethanolamine.

1-Methyl-3-(2-hydroxyethyl)thymine (12). Compound 11 ( $7 \mathrm{~g} ; 0.05 \mathrm{~mol})$ was dissolved in $200 \mathrm{ml}$ dimethylformamide (DMF) under reflux, and ethylene carbonate $(4.72 \mathrm{~g}, 0.05 \mathrm{mmol}$ dissolved in $15 \mathrm{ml}$ of DMF) was added dropwise to the solution. The reaction was continued until the system was degassed under reflux (about $2 \mathrm{~h}$ ). The solvent was then removed under reduced pressure and the residue was crystallized from ethanol to obtain 12 in $92.6 \%$ yield $(8.53 \mathrm{~g}) ; \mathrm{mp} 174-175^{\circ} \mathrm{C}$. IR $(\mathrm{KBr}$, $\left.\mathrm{cm}^{-1}\right): 3375,3050,3000,2970,1695,1680$, $1660,1635,1475,1450,1420,1350,1260,1200$, $1145,1066,950,765,675$, and 645. ${ }^{1} \mathrm{H}$ NMR $\left(60 \mathrm{MHz}\right.$, in dimethyl sulfoxide (DMSO) $d_{6}$ at $\left.25^{\circ} \mathrm{C}, \mathrm{ppm}\right): 1.82(\mathrm{~s}, 3 \mathrm{H}), 3.29(\mathrm{~s}, 3 \mathrm{H}), 3.57(\mathrm{t}$, $2 \mathrm{H}), 3.97(\mathrm{t}, 2 \mathrm{H}), 4.75(\mathrm{t}, 1 \mathrm{H})$, and $7.55(\mathrm{~s}, 1 \mathrm{H})$.

Anal. Calcd. for $\mathrm{C}_{8} \mathrm{H}_{12} \mathrm{O}_{3} \mathrm{~N}_{2}: \mathrm{C}, 52.17 \%$; $\mathrm{H}, 6.57 \%$; N, $15.21 \%$. Found: C, $52.23 \%$; $\mathrm{H}, 6.60 \%$; N, $15.21 \%$.

1-Methyl-3-(2-methacryloyloxyethyl-thymine (13) $\left(M A O T^{3} M e^{1}\right)$. Methacrylic anhydride $(3.0 \mathrm{ml}, 0.024 \mathrm{~mol})$ was added to a solution of $12(3.68 \mathrm{~g}, 0.02 \mathrm{~mol})$ in pyridine $(20 \mathrm{ml})$, and the solution was stirred for $60 \mathrm{~h}$ at room temperature. Pyridine was removed under reduced pressure, and the oily residue was dissolved in a saturated aqueous solution of sodium bicarbonate to remove excess methacrylic anhydride. After extraction with diethyl ether and evaporation of the solvent, the re- sidue was crystallized from cyclohexane to obtain 13 in $48 \%$ yield $(2.43 \mathrm{~g})$; $\mathrm{mp} 69-70{ }^{\circ} \mathrm{C}$. IR $\left(\mathrm{KBr}, \mathrm{cm}^{-1}\right)$ : $3150,2960,2780,1690,1660$, $1470,1440,1410,1350,1300,1280,1260,1230$, $1150,1130,1010,950,870$, and $750 .{ }^{1} \mathrm{H}$ NMR $\left(60 \mathrm{MHz}\right.$, in DMSO- $d_{6}$ at $25^{\circ} \mathrm{C}$, ppm): $1.82(\mathrm{~s}$, $6 \mathrm{H}), 3.22(\mathrm{~s}, 3 \mathrm{H}), 4.1-4.3(\mathrm{~m}, 4 \mathrm{H}), 5.67(\mathrm{~s}$, $1 \mathrm{H}), 5.92(\mathrm{~s}, 1 \mathrm{H})$, and $7.55(\mathrm{~s}, 1 \mathrm{H})$.

Anal. Calcd. for $\mathrm{C}_{12} \mathrm{H}_{16} \mathrm{O}_{4} \mathrm{~N}_{2}:$ C, $57.14 \%$; $\mathrm{H}, 6.39 \%$; N $11.11 \%$. Found: C, $57.14 \%, \mathrm{H}$, $6.39 \% ; \mathrm{N}, 11.01 \%$.

\section{Polymer Synthesis}

Poly[1-methacryloyloxyethythymine]; Poly$\left(M A O T^{1}\right)(1)$. Poly(MAOT $\left.{ }^{1}\right)(1)$ was prepared by free radical polymeization of the corresponding monomer according to the literature. $^{3}$ The molecular weight of the polymer was determined by gel permeation chromatography (GPC) to be 246000 .

Poly [1-methacryloyloxyethyl-3-methylthymine]; Poly $\left(M_{A O T^{1}} \mathrm{Me}^{3}\right)$ (2). Poly(MAO$\mathrm{T}^{1} \mathrm{Me}^{3}$ ) (2) was prepared by methylation of poly $\left(\mathrm{MAOT}^{\mathbf{1}}\right)$ (1) with methyl iodide in DMSO and potassium carbonate at room temperature for $24 \mathrm{~h}$, by the same method as in the literature. ${ }^{11}$

Poly[1-methyl-3-(2-methacryloyloxyethyl)thymine]; $\operatorname{Poly}\left(M A O T^{3} \mathrm{Me}^{1}\right)$ (3). Monomer $13\left(0.25 \mathrm{~g}, 0.1 \mathrm{moll}^{-1}\right)$ and AIBN $(0.0016 \mathrm{~g}$, $\left.0.01 \mathrm{moll}^{-1}\right)$ were dissolved in $10 \mathrm{ml} \mathrm{DMF}$, and radical polymerization was carried out for $24 \mathrm{~h}$ at $60^{\circ} \mathrm{C}$. After the reaction, the solution was precipitated in methanol to obtain polymer (3) in $87 \%$ yield $(0.22 \mathrm{~g})$. The molecular weight of the polymer obtained by GPC was found to be 146000 . IR $\left(\mathrm{KBr}, \mathrm{cm}^{-1}\right): 2920,1700$, $1640,1460,1360,1270,1160,1030$, and 780 . ${ }^{1} \mathrm{H}$ NMR $\left(100 \mathrm{MHz}\right.$, in DMSO- $d_{6}, 150^{\circ} \mathrm{C}$, ppm): 0.7 (s, 3H), $1.8(\mathrm{~s}, 3 \mathrm{H}), 1.6-2.0(\mathrm{~m}, 2 \mathrm{H})$, $3.3(\mathrm{~s}, 3 \mathrm{H}), 4.2(\mathrm{~s}, 4 \mathrm{H})$, and $7.4(\mathrm{~s}, 1 \mathrm{H})$.

Anal. Calcd. for $\mathrm{C}_{12} \mathrm{H}_{16} \mathrm{O}_{4} \mathrm{~N}_{2}:$ C: $57.14 \%$ $\mathrm{H}: 6.39 \% \mathrm{~N}: 11.11 \%$. Found: $\mathrm{C}: 56.57 \% ; \mathrm{H}$ : $6.45 \%$; N: $11.01 \%$.

Poly $\left[M A O T^{1}-\right.$ co-MAOT $\left.{ }^{3} \mathrm{Me}^{1}\right](\mathbf{4 a}-\mathbf{4 e}) . \mathrm{Co}-$ polymers of $\mathrm{MAOT}^{1}$ and $\mathrm{MAOT}^{3} \mathrm{Me}^{1}$ were 
Table I. Copolymerization of MAOT $^{1}$ with $\mathrm{MAOT}^{3} \mathrm{Me}^{1}$

\begin{tabular}{ccc}
\hline $\begin{array}{c}\text { MAOT }^{1} \text { in } \\
\text { monomer } / \%\end{array}$ & Conversion $/ \%$ a & $\begin{array}{c}\text { MAOT }^{1} \text { in } \\
\text { polymer } / \%\end{array}$ \\
\hline 80 & 89 & 82 \\
70 & 93 & 78 \\
60 & 87 & 66 \\
50 & 83 & 54 \\
40 & 86 & 44 \\
\hline
\end{tabular}

a In DMF at $60^{\circ} \mathrm{C}$ for $24 \mathrm{~h}$; $\left[\mathrm{MAOT}^{1}+\mathrm{MAOT}^{3} \mathrm{Me}^{1}\right.$ ] $=$ $0.1 \mathrm{~mol} \mathrm{l}^{-1},[\mathrm{AIBN}]=0.01 \mathrm{~mol} \mathrm{l}^{-1}$.

prepared by the radical polymerization of various ratios of these monomers according to the method mentioned in the synthesis of poly $\left(\mathrm{MAOT}^{3} \mathrm{Me}^{1}\right)$ (in DMF, $\left[\mathrm{MAOT}^{1}+\right.$ $\left.\mathrm{MAOT}^{3} \mathrm{Me}^{1}\right]=0.1 \mathrm{moll}^{-1}, \quad[\mathrm{AIBN}]=0.01$ moll ${ }^{-1}, 60^{\circ} \mathrm{C}, 24 \mathrm{~h}$ ). The copolymers were obtained by precipitation in excess acetone. The conversions of the monomers are given in Table I. The molecular weight of the copolymer with composition of $\mathrm{MAOT}^{1}-\mathrm{MAOT}^{3} \mathrm{Me}^{1}$ (66:34) was 524000 .

Poly[methacrylic acid-alt-MAOT $\left.{ }^{3} \mathrm{Me}^{1}\right]$ (15). Polymethacrylic anhydride (14) was prepared according to the method in the literature. ${ }^{13}$ The molecular weight of the polymer obtained was about 95000 . This polymer was then dissolved in a DMF-pyridine mixture $(5 \mathrm{ml})$, and $12(12.8 \mathrm{~g}, 0.07 \mathrm{~mol})$ was added to this solution, and stirred for 3 days at $60^{\circ} \mathrm{C}$. After the reaction, the solvent was distilled off under reduced pressure, and the residue was thoroughly washed with acetone and filtered to obtain polymer (15) in $34 \%$ yield $(0.81 \mathrm{~g})$. IR $(\mathrm{KBr}$, $\left.\mathrm{cm}^{-1}\right): 3400,2950,1720,1620,1450,1390$, 1350, 1260, 1140, 1020, and 780 .

Poly[MAOT $T^{1}$-alt-MAOT $\left.\mathrm{Me}^{1}\right]$ (5). To 15 $(0.33 \mathrm{~g}, 0.001 \mathrm{~mol})$ in $3 \mathrm{ml}$ DMF, $1,2-O-$ ethanothymine $^{10}$ (16) $(0.25 \mathrm{~g}, 0.001 \mathrm{~mol})$ was added and the reaction mixture was stirred at $80^{\circ} \mathrm{C}$ for $5 \mathrm{~h}$. After the reaction, the mixture was poured into excess ethanol to obtain polymer (5) as a precipitant in $91 \%$ yield $(0.41 \mathrm{~g})$, IR (KBr, cm $\left.{ }^{-1}\right)$ : 3440, 2900, 1700, 1660, 1640,
$1470,1360,1260,1030$, and $780 .{ }^{1} \mathrm{H}$ NMR $\left(100 \mathrm{MHz}\right.$, in DMSO- $d_{6}$ at $\left.150^{\circ} \mathrm{C}, \mathrm{ppm}\right): 0.6$ $1.4(\mathrm{~m}, 6 \mathrm{H}), 1.8(\mathrm{~s}, 10 \mathrm{H}), 3.3(\mathrm{~s}, 3 \mathrm{H}), 4.0(\mathrm{~s}$, $2 \mathrm{H}), 4.2(\mathrm{~s}, 6 \mathrm{H}), 7.4(\mathrm{~s}, 2 \mathrm{H})$, and $11.3(\mathrm{~s}, 1 \mathrm{H})$.

\section{Photochemical Reactions}

Photolyses of the polymers in solutions were carried out in a $10 \mathrm{~mm}$ quartz cell. All the samples were dissolved in DMSO and the concentration of the polymer solutions were adjusted at $1 \times 10^{-4} \mathrm{moll}^{-1}$ as the thymine unit. The photodimerization was followed by UV spectrophotometer at $270 \mathrm{~nm}$. The light source was a monochromator adjusted at the wavelength $280 \mathrm{~nm}$. The purified nitrogen gas was passed through the solution to displace the air before irradiation and light intensities were determined by potassium actinometry. ${ }^{6}$

Photolyses of the polymer films were carried out with a spectro-irradiator. Solutions of the polymers in DMF were cast on quartz substrates, and the solvents were rejected under vacuum for 1 day to obtain thin films of the polymers. The films were exposed to the irradiation of a $2 \mathrm{KW}$ Xe-Arc lamp through a diffracting latticed window with a narrow wavelength range of UV light centered at $280 \mathrm{~nm}$ $(268-292 \mathrm{~nm})$.

For photosensitivity tests, DMF solutions of the polymers $(10 \%, \mathrm{w} / \mathrm{w})$ were spin coated on the aluminum substrates. The thickness of the films obtained, were about $0.3 \mu \mathrm{m}$. The polymer films were exposed to the irradiation of a UV light through the thin slit of a spectrophotograph by scanning up the aluminum substrates against the light slit, and then were developed in a DMF- $m$-xylene mixed solution under the same conditions (temperature and time).

\section{Instrumentation}

A JASCO SS-25 monochromator with a wavelength at $280 \mathrm{~nm}$ was used as the light source to determine the quantum yields of the resists in solution. Photolyses of the polymer films were carried out with using a Nihon 


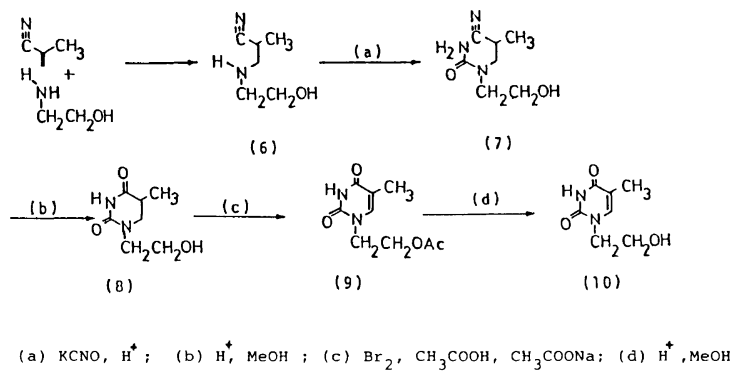

Scheme 2.

Bunko (CRM-FA) spectro-irradiator with a $2 \mathrm{KW}$ Xe-Arc lamp as the light source. The ultraviolet spectra were measured with a Nihon-Bunko (UVIDEC-660) spectrophotometer.

Measurement of the lithographic photosensitivity was made using a Nihon-Spectrophotograph (CT-40) with a $500 \mathrm{~W}$ Xeshort Arc lamp as deep UV light source. The polymer films on aluminum substrates were scanned up through the slit of the illuminating source by a continuous scanning mechanism. The resists were spin coated on the aluminum substrates by a Mikasa spinner $\left(1 \mathrm{H}-\mathrm{D}_{2}\right)$, and the thickness of the resists was measured using a Rank-Tieler Talystep profilemeter.

The molecular weight distribution of the polymers was determined by gel permeation chromatography (GPC) using Toyo Soda HLC CP8000 with a thermostated column TSK gel G4000HT (Toyo Soda Co., $4 \times 10^{3}-$ $4 \times 10^{5} M_{\mathrm{w}}$ ) and a UV detector operated at $270 \mathrm{~nm}$ with DMF as the eluent.

\section{RESULTS AND DISCUSSION}

\section{Material Synthesis}

Hydroxyethyl derivatives of thymine were prepared staring with ethanolamine and methacrylonitrile according to a modified method for 1-alkuluracil as shown in Scheme $2 .^{8}$ The methacrylate monomers were obtained by the reaction of the hydroxyethyl derivatives with methacrylic anhydride. Poly(methacrylate)s having various thymine derivatives
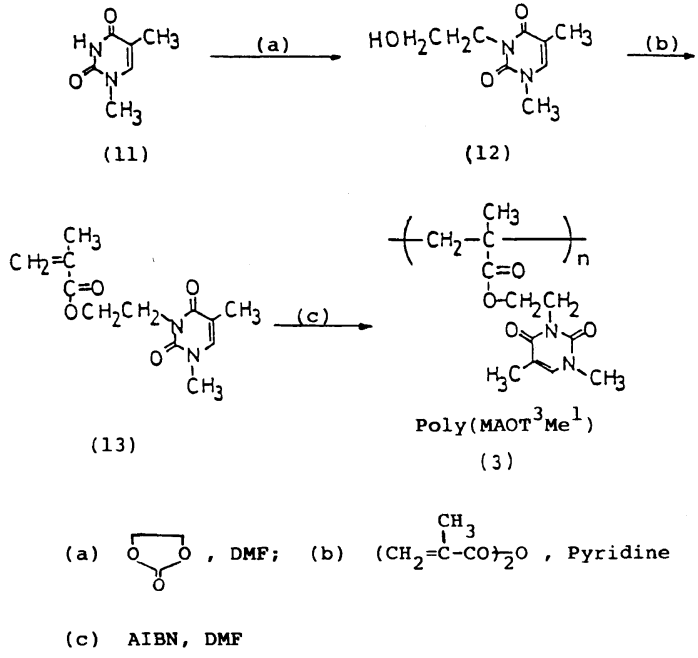

Scheme 3.

(Figure 1) were prepared according to Scheme 3.

Radical polymerization and copolymerization of these monomers were carried out using AIBN as the initiator. Results of the copolymerization are summarized in Table I; the content of each unit was determined by ${ }^{1} \mathrm{H}$ NMR spectra. Poly $\left(\mathrm{MAOT}^{1} \mathrm{Me}^{3}\right)$ was obtained by methylation of poly $\left(\mathrm{MAOT}^{1}\right)$, according to the literature. ${ }^{11}$ The alternate copolymer [poly $\left(\mathrm{MAOT}^{1}\right.$-alt-MAOT $\left.{ }^{3} \mathrm{Me}^{1}\right)$ ] was obtained by reaction of poly(methacrylic anhydride) with the hydroxyethyl derivative of thymine followed by reaction with another cyclic type of thymine derivative, as shown in Scheme 4. 


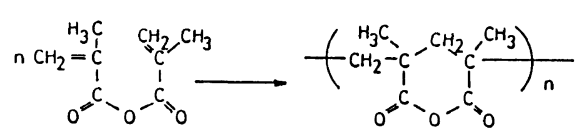

(14)
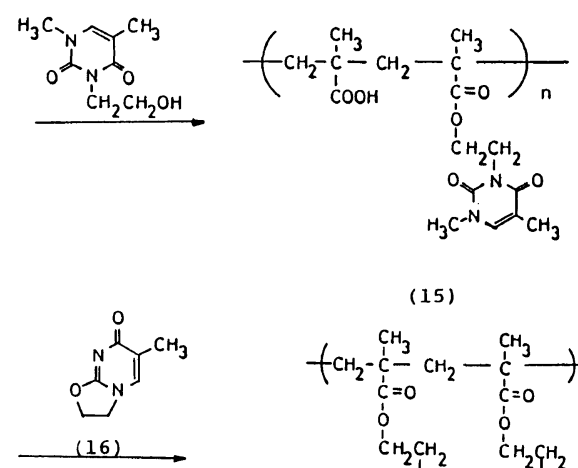

(15)

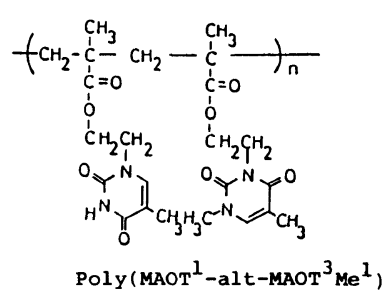

(5)

Scheme 4.

\section{Photolysis}

Photoreaction of the Polymers in Solution. Photochemical reactions of the polymers in dilute solutions were studied to determine the quantum yields of the intramolecular photodimerization of the thymine units along the polymer chain. The quantum yields determined at the wavelenght $280 \mathrm{~nm}$ for all polymers and copolymers are listed in Table II. The values of the molar extinction coefficients and hypochromicities of the polymers based on thymine monomers are also listed in the table.

The hypochromicity generally showed interactions between nucleic acid bases and their stacked conformation in the ground state; the greater the stacked conformation, the higher was the quantum yield. On the other hand, it was known that photodimerization occurs only intramolecularly in dilute solutions of polymers with pendant thymine bases. ${ }^{3}$ Therefore, the quantum yields obtained in Table II indicate the efficiency of the intramolecular photodimerization in each poly-
Table II. Molar extinction coefficients, quantum yields, and hypochromicities of the polymethacrylates with pendant thymine bases

\begin{tabular}{|c|c|c|c|}
\hline Compound & $\varepsilon^{\mathbf{a}}$ & $\Phi_{\mathrm{d}}^{\mathrm{b}}$ & $\mathrm{H} / \% \mathrm{c}$ \\
\hline Poly $\left(\right.$ MAOT $\left.^{3} \mathbf{M e}^{1}\right)$ & 8300 & 0.017 & 7.8 \\
\hline Poly $\left(\right.$ MAOT $\left.^{1}\right)$ & 7990 & 0.0095 & 11.2 \\
\hline Poly $\left(\mathrm{MAOT}^{1} \mathrm{Me}^{3}\right)$ & - & 0.012 & - \\
\hline \multicolumn{4}{|l|}{ Poly(MAOT $\left.{ }^{1}-c o-\mathrm{MAOT}^{3} \mathrm{Me}^{1}\right)$} \\
\hline$(82: 18)$ & 9000 & 0.0038 & 0.0 \\
\hline$(78: 22)$ & 9100 & 0.0046 & 1.1 \\
\hline$(66: 34)$ & 8600 & 0.0044 & 4.4 \\
\hline$(54: 46)$ & 8900 & 0.0065 & 1.1 \\
\hline$(44: 56)$ & 9200 & 0.0096 & 2.2 \\
\hline Poly(MAOT ${ }^{1}$-alt-MAOT $\left.{ }^{3} \mathrm{Me}^{1}\right)$ & 7600 & 0.0059 & 15.5 \\
\hline
\end{tabular}

a Molar extinction coefficient at $272 \mathrm{~nm}$ in DMSO at $25^{\circ} \mathrm{C}$.

b Quantum yield in DMSO.

c Hypochromicity relative to thymine monomer in DMSO at $25^{\circ} \mathrm{C}\left(\varepsilon_{\text {thymine }}=9000\right)$.

mer, and are related to the stacking of the thymine bases and reactivity of the stacked thymine bases for photodimerization.

The quantum yield values were plotted against the composition of copolymers as shown in Figure 2a. The oblique line shows hypothetical quantum yield for the mixture of homopolymers [poly(MAOT $\left.{ }^{1}\right)$ and poly$\left.\left(\mathrm{MAOT}^{3} \mathrm{Me}^{1}\right)\right]$, and the real curve represents the quantum yields of various copolymers of MAOT $^{1}$ and MAOT $^{3} \mathrm{Me}^{1}$. Poly $\left(\mathrm{MAOT}^{3}\right.$ $\mathrm{Me}^{1}$ ) showed a higher quantum yield than poly $\left(\mathrm{MAOT}^{1}\right)$, which suggests that the sterical arrangement of thymine bases in poly$\left(\mathrm{MAOT}^{3} \mathrm{Me}^{1}\right)$ is more favorable for the photodimerization than that of poly $\left(\mathrm{MAOT}^{1}\right)$.

Molecular models indicated that the formation of the thymine photodimers are sterically difficult for the alternate copolymers of MAOT $^{1}$ and MAOT $^{3} \mathrm{Me}^{1}$ but favorable for the homopolymers. These considerations of molecular models may explain the lower quantum yield of the copolymer than those of homopolymers as shown in Figure 2a. The possibility of the adjacent existence of MAOT $^{1}$ and $\mathrm{MAOT}^{3} \mathrm{Me}^{1}$ increased in random copoly- 
mer of $\mathrm{MAOT}^{3} \mathrm{Me}^{1}$ and $\mathrm{MAOT}^{1}$, and hence the favorable stacking conformations of thymine units decreased in such a way that the photodimerization would occur sterically with difficulty. The alternate copolymer [poly-

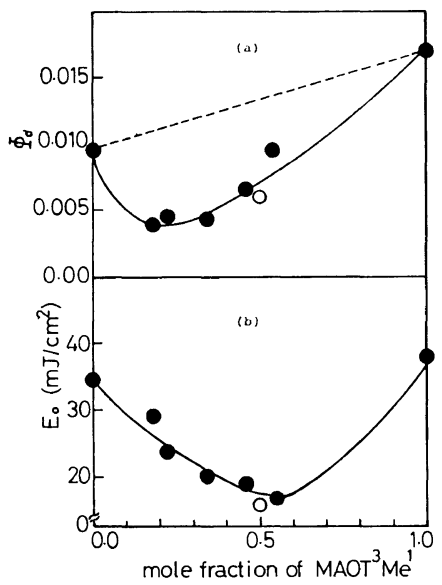

Figure 2. (a) Quantum yields for intramolecular photodimerization of homopolymers and copolymers: O, poly $\left(\mathrm{MAOT}^{1}\right.$-alt-MAOT ${ }^{3} \mathrm{Me}^{1}$ ). (b) The minimum required energy for remaining the pattern of homopolymers and copolymers: $\bigcirc$, poly $\left(\mathrm{MAOT}^{1}\right.$-altMAOT $^{3} \mathrm{Me}^{1}$ ).
$\left(\mathrm{MAOT}^{1}\right.$-alt-MAOT $\left.\left.{ }^{3} \mathrm{Me}^{1}\right)\right]$, in which $\mathrm{MAOT}^{1}$ units and $\mathrm{MAOT}^{3} \mathrm{Me}^{1}$ units exist certainly next to each other, showed lower quantum yields than the random copolymer of MAOT $^{1}$ and $\mathrm{MAOT}^{3} \mathrm{Me}^{1}$. This is also evidence for the large strain in the polymer chains for photodimerization of the adjacent MAOT $^{1}$ and $\mathrm{MAOT}^{3} \mathrm{Me}^{1}$ rather than $\mathrm{MAOT}^{1}$ units or MAOT $^{3} \mathrm{Me}^{1}$ units.

Photoreaction in the Solid State. The rates of photodimerization of thymine units in the side chains of the poly $\left(\mathrm{MAOT}^{1}\right)$, poly$\left(\mathrm{MAOT}^{3} \mathrm{Me}^{1}\right)$, and poly $\left(\mathrm{MAOT}^{1}-\mathrm{co}\right.$-MAO$\left.\mathrm{T}^{3} \mathrm{Me}^{1}\right)(66 / 34)$ were measured in the solid state. Figure 3 shows the percent of thymine bases remaining in the polymer chain against irradiation energy at $280 \mathrm{~nm}$. The formation of thymine dimer units was then confirmed by reversible photodissociation of thymine dimer units by irradiation of a narrow wavelength range of UV light centered at $249 \mathrm{~nm}$, as shown in the same figure. The initial rate of the disappearance of thymine units, where there were very few isolated thymine bases grafted to the polymer chains, ${ }^{14}$ was ob-

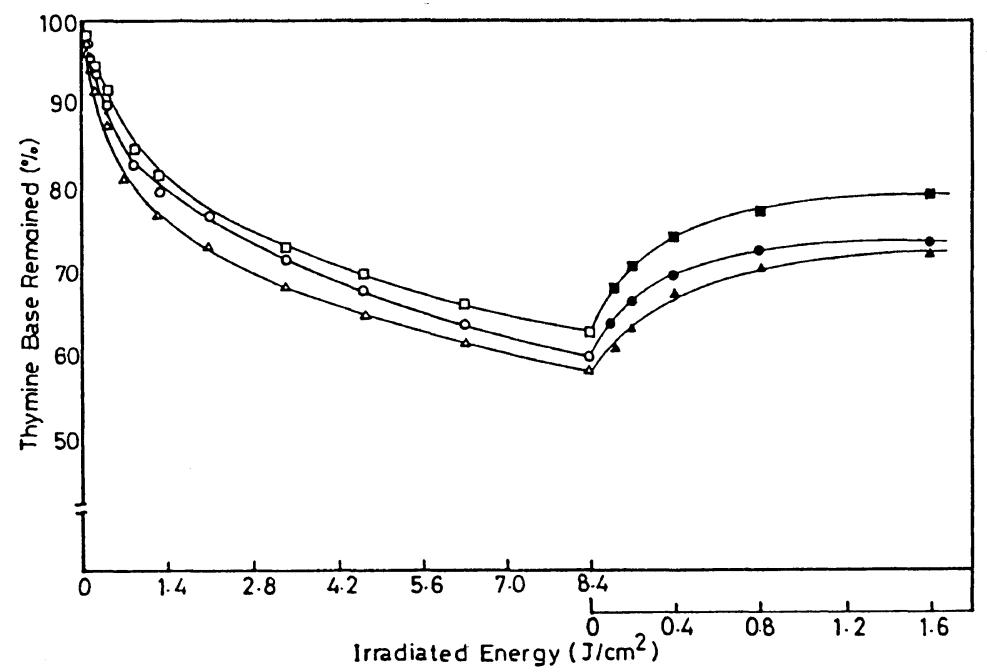

Figure 3. Photodimerization and photodisintegration of thymine units and their photodimers in the side chains of the homopolymers and copolymers in the film state. Photodimerization reaction as a function of irradiated energy at $280 \mathrm{~nm}: \square$, poly $\left(\mathrm{MAOT}^{1}\right) ; \bigcirc, \operatorname{poly}\left(\mathrm{MAOT}^{3} \mathrm{Me}^{1}\right) ; \triangle$, poly $\left(\mathrm{MAOT}^{1}-c o-\right.$ MAOT $\left.^{3} \mathrm{Me}^{1}\right)(66: 34)$. Photodissociation reaction as a function of irradiated energy at $249 \mathrm{~nm}$ : poly $\left(\mathrm{MAOT}^{1}\right) ; \boldsymbol{O}, \operatorname{poly}\left(\mathrm{MAOT}^{3} \mathrm{Me}^{1}\right) ; \boldsymbol{\Delta}, \operatorname{poly}\left(\mathrm{MAOT}^{1}-\right.$ co $\left.\mathrm{MAOT}^{3} \mathrm{Me}^{1}\right)(66: 34)$. 


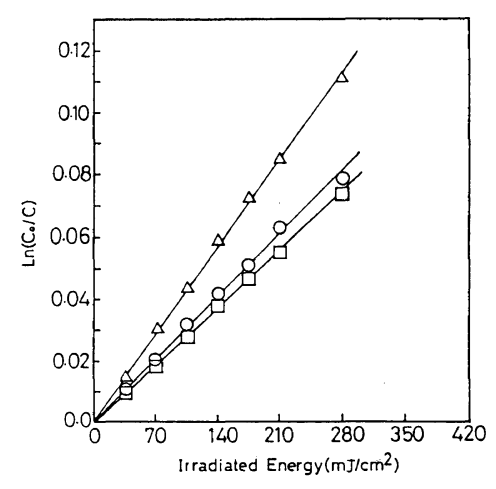

Figure 4. Initial photodimerization rate of thymine units in the side chain of the polymers and copolymers in the film state: $\square$, poly $\left(\mathrm{MAOT}^{1}\right)$; $\bigcirc$, poly-

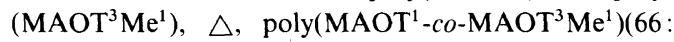
34).

tained by plotting the $\ln C_{0} / C$ against irradiation energy at $280 \mathrm{~nm}$ as shown in Figure 4 , where $C_{0}$ and $\mathrm{C}$ are the concentrations of thymine unit before and after irradiation of various doses, respectively.

The initial quantum yields of the polymers in the film state were obtained by using eq $1^{15}$

$$
\phi_{\mathrm{d}}=\left[1 /\left(\sigma_{\mathrm{a}}\right)\left(C_{0}\right)\right][\Delta C / \Delta L]
$$

where $\sigma_{\mathrm{a}}$ is the absorption cross section of the polymer, $\Delta C$ is the change in thymine concentration, and $\Delta L$ is the increment of the light exposure. The quantum yields and maximum conversions for photodimerization reaction of these polymers are listed in Table III.

It was found that the quantum yields of the homopolymers in the film state were about 59 times of those in the solution. The high quantum yield in the film state suggests that the thymine bases fixed in the film state, and the possibility for intermolecular reaction increases. However, the stacking conformation of the thymine bases in the side chain of the homopolymers are favorable for the intramolecular photodimerization and hence intramolecular photodimerization should occur efficiently even in the film state.

Quantum yields of the copolymers were lower in solution (Figure 2a), and higher in the
Table III. Quantum yields and maximum photodimerization conversion of thymine bases in polymethacrylates with pendant thymine bases in the film state

\begin{tabular}{lcc}
\hline Polymer & $\Phi_{\mathrm{d}}$ & Conv $_{\max } / \%$ \\
\hline Poly(MAOT $^{1}$ ) & 0.086 & 40 \\
Poly(MAOT $\left.^{3} \mathrm{Me}^{1}\right)$ & 0.080 & 37 \\
Poly(MAOT $^{1}-$ co-MAOT $\left.^{3} \mathrm{Me}^{1}\right)$ & & \\
$\quad(66: 34)$ & 0.159 & 42 \\
\hline
\end{tabular}

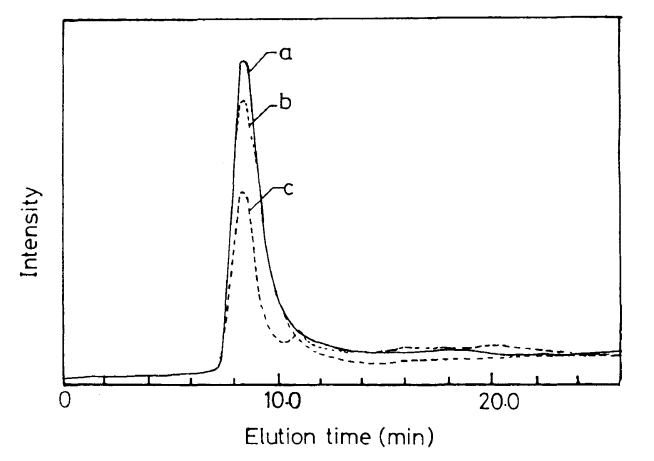

Figure 5. Gel permeation chromatograms of poly$\left(\mathrm{MAOT}^{1}\right.$-co-MAOT $\left.{ }^{3} \mathrm{Me}^{1}\right)(66: 34)$, in dilute solution exposed to the irradiation of UV light at $280 \mathrm{~nm}$; (a), before irradiation, $M_{n}=5.42 \times 10^{5}, M_{w} / M_{n}=5.58$; (b, c), after exposure of 4.2 and $35 \mathrm{~J} \mathrm{~cm}^{-2}$ doses.

film state (Table III) than those of the homopolymers. This suggests that the intermolecular photodimerization of thymine bases occurs preferentially for copolymers in the film state.

\section{GPC Study of the Polymers}

The molecular weight changes by photodimerizations were measured by GPC. The chromatograms before and after photochemical reaction of poly $\left(\mathrm{MAOT}^{1}-\mathrm{co}-\mathrm{MAOT}^{3} \mathrm{Me}^{1}\right)$ $(66: 34)$ in DMF solution are shown in Figure 5 . The molecular weight of this copolymer was higher than that of homopolymers (based on standard polystyrene), as shown in Figures 7 and 8 . Figure 5 shows that the photodimerization of thymine units in solution is predominantly an intramolecular reaction, and no intermolecular photodimerization leading to an increase in molecular weight of the polymer 


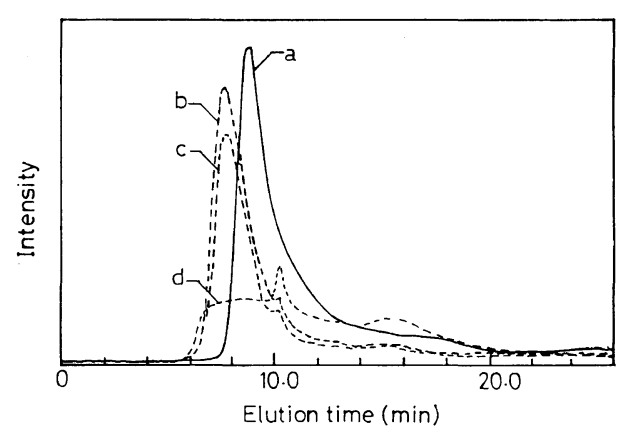

Figure 6. Gel permeation chromatograms of poly$\left(\right.$ MAOT $^{1}$-co-MAOT $\left.{ }^{3} \mathrm{Me}^{1}\right)(66: 34)$, in the film state exposed to the irradiation of UV light at $280 \mathrm{~nm}$ : (a), before irradiation; $(b-d)$, after exposure of $0.42,2.52$, and $6.3 \mathrm{~J} \mathrm{~cm}^{-2}$ doses.

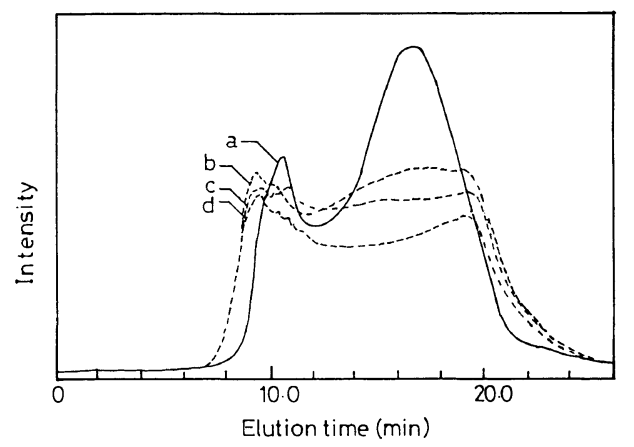

Figure 7. Gel permeation chromatograms of poly$\left(\mathrm{MAOT}^{1}\right)$, in the film state exposed to the irradiation of UV light at $280 \mathrm{~nm}$ : (a), before irradiation, $M_{n}=$ $2.46 \times 10^{5}, M_{w} / M_{n}=3.5$; (b-d), after exposure of 0.84 , 2.49 , and $18.90 \mathrm{~mJ} \mathrm{~cm}^{-2}$ dose.

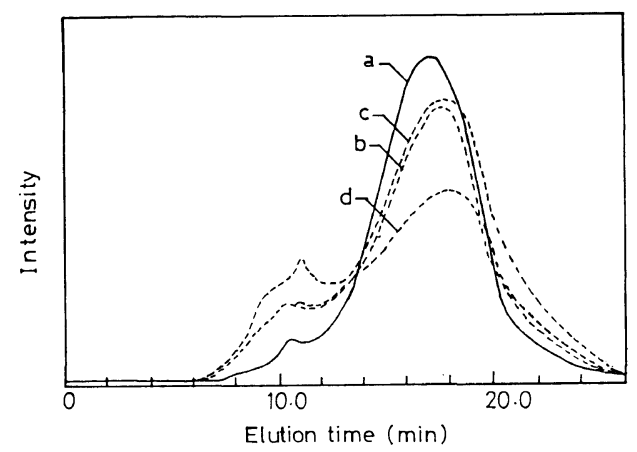

Figure 8. Gel permeation chromatograms of poly$\left(\mathrm{MAOT}^{3} \mathrm{Me}^{1}\right.$ ), in the film state exposed to the irradiation of UV light at $280 \mathrm{~nm}$ : (a), before irradiation, $M_{n}=$ $1.46 \times 10^{5}, M_{w} / M_{n}=3.5$; (b-d), after exposure of 0.63 , 2.52 , and $18.90 \mathrm{~J} \mathrm{~cm}^{-2}$ doses. occurs. On the other hand, in the film state (Figure 6), an increase of molecular weight was observed due to the intermolecular photodimerization of thymine units to form photocrosslinking.

The photodimerization of homopolymers in the film state also caused increase in their molecular weights as shown in Figures 7 $\left[\operatorname{poly}\left(\mathrm{MAOT}^{1}\right)\right]$ and $8\left[\operatorname{poly}\left(\mathrm{MAOT}^{3} \mathrm{Me}^{1}\right)\right]$. These figures show that polymer chains with the same molecular weights as those before irradiation existed after irradiation. This suggests that the intramolecular and intermolecular reactions occurs simultaneously. However, Figure 6 for the copolymer showed a higher photo-crosslinking rate by intermolecular photodimerization. This indicates that poly $\left(\mathrm{MAOT}^{1}-\right.$ co-MAOT $\left.{ }^{3} \mathrm{Me}^{1}\right)$ can be a highly sensitive polymer as negative type photoresist.

\section{Lithographic Photosensitivity and Its Relation to Quantum Yield}

In order to apply thymine polymers to deepUV photoresist for integrate circuit production, a primary photosensitivity evaluation was carried out. The photosensitivity evaluation of the various polymers was performed in the film state, and their relation to the quantum yields in solution and film state was considered. The photosensitivity range of each polymer, the maximal sensitive wavelength, and the gel dose $\left(\mathrm{E}_{0}\right)$ are listed in Table IV. The gel doses at the maximal wavelength are also plotted against copolymer composition as shown in Figure $2 b$.

A comparison of Figures $2 \mathrm{a}$ and $2 \mathrm{~b}$ shows that the quantum yield in solution is related to photosensitivity in the film state. The copolymers which had lower quantum yield in the solution, showed higher photosensitivity than those of homopolymers. This finding was supported by comparing the quantum yields of the polymers in the film state (Table III) and GPC data. The copolymer of poly(MAOT ${ }^{1}-\mathrm{co}$ MAOT $\left.^{3} \mathrm{Me}^{1}\right)(66: 34)$, which had a low quantum yield in solution (Figure $2 \mathrm{a}$ ), the highest quantum yield in the film state (Table III) and 
Table IV. Lithographic evaluations of polymethacrylates with pendant thymine bases

\begin{tabular}{|c|c|c|c|}
\hline Polymer & $\lambda / \mathrm{nm}^{\mathrm{a}}$ & $\lambda \max / \mathrm{nm}^{\mathrm{b}}$ & $\mathrm{E}_{0} / \mathrm{mJ} \mathrm{cm}^{-2 \mathrm{c}}$ \\
\hline $\operatorname{Poly}\left(\mathrm{MAOT}^{3} \mathrm{Me}^{1}\right)$ & $230-305$ & 280 & 38.0 \\
\hline Poly $\left(\right.$ MAOT $\left.^{1}\right)$ & $230-300$ & 280 & 34.6 \\
\hline Poly $\left(\mathrm{MAOT}^{1} \mathrm{Me}^{3}\right)$ & $230-305$ & 280 & 16.7 \\
\hline Poly(MAOT $\left.{ }^{1}-c o-\mathrm{MAOT}^{3} \mathrm{Me}^{1}\right)(82: 18)$ & $250-305$ & 280 & 28.0 \\
\hline$(78: 22)$ & $230-305$ & 280 & 23.4 \\
\hline$(66: 34)$ & $230-310$ & 280 & 20.3 \\
\hline$(54: 46)$ & $230-310$ & 280 & 18.8 \\
\hline$(44: 56)$ & $230-310$ & 280 & 16.7 \\
\hline Poly $\left(\mathrm{MAOT}^{1}\right.$-alt-MAOT $\left.{ }^{3} \mathrm{Me}^{1}\right)$ & $200-315$ & 270 & 15.8 \\
\hline
\end{tabular}

a Photosensitive wavelength range.

b Maximal photosensitive wavelength.

c Minimum required energy for photo-crosslinking at the maximal wavelength.

high rate of crosslinking (Figure 6), showed higher photosensitivity than homopolymers (Table IV). Therefore, polymers with lower quantum yields of intramolecular photodimerization showed higher photosensitivity caused by intermolecular photodimerization. These results revealed that polymers of high photosensitivity can be obtained by suppression of intramolecular photodimerization and intensifying the intermolecular photodimerization.

However, the polymer composition of the lowest quantum yield in solution is not the same as that of the highest sensitivity in the film state. This is due to the fact that sensitivity is evaluated in this determination after development, and many factors interfere besides the photo-crosslinking reaction, such as the solubility of the polymer for film fabrication, adherence of the polymers solution to the substrates, molecular weights of the unirradiated polymers, and the choice of the developers. Therefore the polymer of the highest photosensitivity does not agree with the polymer of the lowest intramolcular quantum yield.

\section{CONCLUSION}

Poly(methacrylate)s with different sterical arrangements of thymine bases in their side chains were prepared and their photochemical reactions were studied. Evaluation of lithographic photosensitivity of these polymers revealed the following: The alternate copolymer of $\mathrm{MAOT}^{1}$ and $\mathrm{MAOT}^{3} \mathrm{Me}^{1}$ was the most highly photosensitive polymer, and the photosensitivity of the copolymers increased with increasing content of adjacent MAOT $^{1}$ $\mathrm{MAOT}^{3} \mathrm{Me}^{1}$ in the side chains of the copolymers. This indicates that polymers of high photosensitivity values can be obtained by suppression of intramolecular photodimerization and intensifying intermolecular photodimerization.

Acknowledgment. The authors express grateful acknowledgment to Japan Synthetic Rubber Co., for the photosensitivity evaluation of the thymine polymers.

\section{REFERENCES}

1. L. F. Thompson, C. G. Willson, and M. J. Bowden, "Introduction to Microlithography," ACS Symposium Series, 219, 1983.

2. L. F. Thompson, C. G. Willson, and J. M. J. Frechet, "Materials for Microlithography," ACS Symposium series, 2661984.

3. Y. Kita, Y. Inaki, and K. Takemoto, J. Polym. Sci., Polym. Chem. Ed., 18, 427 (1980).

4. Y. Kita, T. Uno, Y. Inaki, and K. Takemoto, $J$. Polym. Sci., Polym. Chem. Ed., 19, 477 (1981).

5. Y. Kita, T. Uno, Y. Inaki, and K. Takemoto, $J$. Polym. Sci., Polym. Chem. Ed., 19, 2347 (1981). 
6. Y. Inaki, S. Fukunaga, Y. Suda, and K. Takemoto, J. Polym. Sci., Polym. Chem. Ed., 23, 119 (1985).

7. Y. Inaki, S. Fukunaga, K. Takemoto, and Y. Harita, J. Polym. Sci., Polym. Chem. Ed., in contribution.

8. W. W. Zorbach and R. S. Tipson, "Synthetic Procedures in Nucleic Acid Chemistry," Vol. I, Academic Press, New York, N.Y., 1968, p 63.

9. W. W. Zorbach and R. S. Tipson, "Synthetic Procedures in Nucleic Acid Chemistry," Vol. I, Academic Press, New York, N.Y., 1968, p 109.

10. Y. Kita, H. Futagawa, Y. Inaki, and K. Takemoto, Polym. Bull., 2, 195 (1980).
11. S. B. Fang, Y. Inaki, and K. Takemoto, J. Polym. Sci., Polym. Chem. Ed., 22, 2455 (1984).

12. S. B. Fang, Y. Inaki, and K. Takemoto, Polym. J., 17, 443 (1985).

13. J. A. Moore, Macromolecular Syntheses, Collective Vol., 1, 41 (1977).

14. Y. Kita, T. Uno, Y. Inaki, and $\mathrm{K}$. Takemoto, $J$. Polym. Sci., Polym. Chem. Ed., 19, 1733 (1981).

15. G. J. Fisher and H. E. Johns, "Photochemistry and Photobiology of Nucleic Acids," Vol. I, S. Y. Wang, Ed., Academic Press, New York, 1976, p. 234. 